\title{
The Pro12Ala Polymorphism of PPAR- $\gamma$ Gene Is Associated with Sepsis Disease Severity and Outcome in Chinese Han Population
}

\author{
Guoda Ma, ${ }^{1}$ Haiyang Wang, ${ }^{2}$ Guixi Mo, ${ }^{3}$ Lili Cui, ${ }^{1}$ You Li, ${ }^{1}$ Yiming Shao, ${ }^{4}$ Xin Liu, ${ }^{3}$ \\ Yuliu Xie, ${ }^{4}$ Jia Li, ${ }^{4}$ Jiawu Fu, ${ }^{1}$ Hua Tao, ${ }^{1}$ Bin Zhao, ${ }^{1}$ Liangqing Zhang, ${ }^{3}$ and Keshen Li ${ }^{1}$ \\ ${ }^{1}$ Guangdong Key Laboratory of Age-Related Cardiac and Cerebral Diseases, \\ Affiliated Hospital of Guangdong Medical College, Zhanjiang 524001, China \\ ${ }^{2}$ Department of Vascular Surgery of General Surgery, The First Affiliated Hospital of Harbin Medical University, \\ Harbin 150001, China \\ ${ }^{3}$ Department of Anesthesiology, Affiliated Hospital of Guangdong Medical College, Zhanjiang 524001, China \\ ${ }^{4}$ Intensive Care Unit, Affiliated Hospital of Guangdong Medical College, Zhanjiang 524001, China \\ Correspondence should be addressed to Liangqing Zhang; zhanglq1970@163.com and Keshen Li; likeshen1971@126.com
}

Received 11 April 2014; Revised 2 July 2014; Accepted 9 July 2014; Published 20 July 2014

Academic Editor: Todd Leff

Copyright (C) 2014 Guoda Ma et al. This is an open access article distributed under the Creative Commons Attribution License, which permits unrestricted use, distribution, and reproduction in any medium, provided the original work is properly cited.

Peroxisome proliferator-activated receptor- $\gamma(\operatorname{PPAR}-\gamma)$ is a ligand-binding nuclear receptor, and its activation plays a prominent role in regulating the inflammatory response. Therefore, PPAR- $\gamma$ has been suggested as a candidate gene for sepsis. In the present study, we investigated the association between the Prol2Ala polymorphism of PPAR- $\gamma$ and sepsis in a Han Chinese population. A total of 308 patients with sepsis and 345 healthy controls were enrolled in this study. Genotyping was performed using the polymerase chain reaction-ligation detection reaction (PCR-LDR) method. No significant differences were detected in the allele and genotype distributions of the PPAR- $\gamma$ Prol2Ala SNP between septic patients and controls $(P=0.622$ for genotype; $P=0.629$ for allele). However, stratification by subtypes (sepsis, septic shock, and severe sepsis) revealed a statistically significant difference in the frequency of the Ala allele and Ala-carrier genotype between the patients with the sepsis subtype and the healthy controls ( $P=0.014$ for allele and $P=0.012$, for genotype). Moreover, significant differences were found in the frequency of the Ala allele and genotype between the sepsis survivors and nonsurvivors (all $P=0.002)$. In the survivors, the PPAR- $\gamma$ Prol2Ala genotype was significantly associated with decreased disease severity and recovery time (all $P<0.001$ ). Thus, genetic polymorphism is thought to play a role in the development and outcome of sepsis.

\section{Introduction}

Sepsis is a clinical entity involving a massive systemic inflammatory response, which may result in septic shock, multiple organ system failure, and death [1]. Although the methods of treatment are constantly updated and refined, sepsis and septic shock remain the most prevalent causes of death in intensive care units (ICUs). Recently, peroxisome proliferatoractivated receptor gamma (PPAR- $\gamma$ ) was described as playing a role in modulating the pathological status of sepsis by regulating energy metabolism, inflammation, and immune cell function [2].

PPAR- $\gamma$, a member of the nuclear hormone receptor superfamily, is a ligand-binding nuclear receptor whose activation controls the inflammatory response [3]. PPAR- $\gamma$ has been shown to regulate inflammatory status by controlling the differentiation of monocytes and macrophages and by suppressing the expression of inflammatory cytokines, such as tumor necrosis factor alpha (TNF- $\alpha$ ), interleukin-1 beta (IL-1 $\beta$ ), inducible cyclooxygenase-2 (COX-2), and other downstream markers of inflammation [3-5]. In animal models of sepsis and septic shock, PPAR- $\gamma$ agonist pretreatment markedly attenuated inflammation compared with controls $[6,7]$. Therefore, PPAR- $\gamma$ has been suggested to be beneficial in sepsis. However, PPAR- $\gamma$ induces apoptosis, and the death of immune cells, especially T lymphocytes, is generally considered deleterious [2]. Under these circumstances, a second infection cannot be adequately cleared, leading to septic 
shock and multiple organ dysfunction syndrome. Because of the profound involvement of PPAR- $\gamma$ in sepsis, we explored the possibility of PPAR- $\gamma$ as a candidate gene for sepsis susceptibility.

The most common functional polymorphism in the PPAR- $\gamma$ gene is a CCA-to-GCA missense mutation (rs1801282) in codon 12 of exon $\mathrm{B}$, which results in the replacement of proline 12 with alanine (Prol2Ala) [8] and a reduction in the transcriptional activity of PPAR- $\gamma$ [9]. Previous studies have examined the PPAR- $\gamma$ Prol2Ala polymorphism in a variety of inflammatory diseases, such as atherosclerosis, psoriatic arthritis, inflammatory bowel disease, and multiple sclerosis [10-13], but none have documented an association between this polymorphism and sepsis. Therefore, we conducted a hospital-based case-control study to investigate whether this functional polymorphism of the PPAR- $\gamma$ gene affects the risk, disease severity, and outcome of sepsis in a Chinese Han population.

\section{Materials and Methods}

2.1. Participant Recruitment. In this study, all the subjects were recruited from the Department of Emergency and ICU of the Affiliated Hospital of Guangdong Medical College between March 2011 and October 2013. Blood samples were collected from the subjects upon the diagnosis of sepsis, severe sepsis, or septic shock. These patients were diagnosed with sepsis, severe sepsis, or septic shock according to the 1991 ACCP/SCCM Joint Meeting [14] and the diagnostic criteria developed at the 2001 International Sepsis Definition Conference [15]. Patients below 18 years of age or suffering from diabetes, immunological diseases, or malignancies were excluded from this study. A total of 308 patients with sepsis were observed during the ICU stay until death or hospital discharge occurred. The Acute Physiology and Chronic Health Evaluation II (APACHE-II) and Sequential Organ Failure Assessment (SOFA) scores were determined on the day of ICU admission and were used to evaluate illness severity and organ dysfunction/failure, respectively. Based on 28-day survival data, the patients with sepsis were further divided into a survivor group ( $\geq 28$-day survival) and a nonsurvivor group (<28-day survival). All the patients were observed for 28-day survival, which was calculated from the date of the primary diagnosis of sepsis. Upon admission to the ICU, patients with sepsis underwent the daily collection of physiologic and laboratory data, for example, gender, age, chronic disease status, cause of sepsis, site of infection, chief complications, duration of ICU stay, duration of hospital stay, prognosis, APACHE-II scores, and SOFA scores. Concurrently, 345 healthy Chinese Han individuals were genotyped and functioned as a control population for the genotype analysis. The Ethics Committee of the Affiliated Hospital of Guangdong Medical College approved this study, and informed consent was obtained from the patients and/or their family members.

2.2. DNA Extraction and Genotyping. Genomic DNA was isolated from the EDTA blood samples collected from all of the patients and controls using the Blood DNA Kit (Tiangen Biotech, Beijing, China) according to the manufacturer's instructions. For each sample, the PPAR- $\gamma$ Prol2Ala genotype was determined using the polymerase chain reactionligation detection reaction (PCR-LDR) method. The PCR primers for Pro12Ala were as follows: forward primer $5^{\prime}$ TGATGTCTTGACTCATGGGTGT-3' and reverse primer $5^{\prime}$-TACATAAATGCCCCCACGTC-3'. PCR was performed in a Perkin-Elmer GeneAmp PCR System 9600 (Applied Biosystems, USA) in a total reaction volume of $20 \mu \mathrm{L}$ containing $1 \mu \mathrm{L}$ of genomic DNA, $2 \mu \mathrm{L}$ of $1 \times$ Taq buffer, $0.4 \mu \mathrm{L}$ of each primer, $2 \mu \mathrm{L}$ of dNTPs, $0.3 \mu \mathrm{L}$ of Qiagen HotStarTaq polymerase (Qiagen, Germany), and $9.8 \mu \mathrm{L}$ of $\mathrm{H}_{2} \mathrm{O}$. The amplification parameters were as follows: denaturation at $95^{\circ} \mathrm{C}$ for $15 \mathrm{~min} ; 35$ cycles of denaturation at $94^{\circ} \mathrm{C}$ for $30 \mathrm{~s}$, annealing at $57^{\circ} \mathrm{C}$ for $90 \mathrm{~s}$ and extension at $72^{\circ} \mathrm{C}$ for $60 \mathrm{~s}$; and a final extension step at $72^{\circ} \mathrm{C}$ for $10 \mathrm{~min}$. The probes for LDR were as follows: $5^{\prime}$-P-GTCAATAGGAGAATCTCCCAGAGT-FAM-3', with a phosphorylated $5^{\prime}$ end and a 6carboxyXuorescein (FAM)-labeled $3^{\prime}$ end; a C-specific probe, $5^{\prime}$-TGTATCAGTGAAGGAATCGCTTTCTGG-3'; and a G-specific probe, $5^{\prime}$-TTTGTATCAGTGAAGGAATCGCTTTCTGC-3'. A ligation reaction was performed with each PCR product; the final volume of $10 \mu \mathrm{L}$ contained $2 \mu \mathrm{L}$ of PCR product, $1 \mu \mathrm{L}$ of $1 \times$ Taq DNA ligase buffer, $1 \mu \mathrm{L}$ of probe mixture, 2 U of Taq DNA ligase (New England Biolabs, USA), and $6.95 \mu \mathrm{L}$ of $\mathrm{H}_{2} \mathrm{O}$. The reaction conditions for LDR were as follows: denaturation at $95^{\circ} \mathrm{C}$ for $2 \mathrm{~min}$, followed by 30 cycles of $94^{\circ} \mathrm{C}$ for $15 \mathrm{~s}$ and $50^{\circ} \mathrm{C}$ for $25 \mathrm{~s}$. The fluorescent LDR products were analyzed using an ABI 377 DNA Sequencer (Applied Biosystems, USA).

2.3. Statistical Analysis. The statistical analysis was performed with SPSS version 19.0 (SPSS Inc., Chicago, IL, USA). The results for continuous variables with normal distributions are provided as means \pm standard deviations (SD). Student's $t$-test was performed to compare means between two groups. The genotype distributions of all the groups were assessed for deviations from Hardy-Weinberg equilibrium. Allele and genotype frequencies were compared using the chi-squared test or Fisher's exact two-tailed tests when appropriate. Kaplan-Meier survival analysis in 28 days was used to explore the mortality differences. The log-rank test was used to evaluate the univariate relationship between the PPAR- $\gamma$ Prol2Ala genotype and clinical outcome. Values of $P<0.05$ were considered statistically significant.

\section{Results}

3.1. Clinical Characteristics. The baseline characteristics and clinical data of all the subjects are shown in Table 1. The average age and sex distribution did not differ significantly between the sepsis and healthy control groups or between the survivor and nonsurvivor groups. The respiratory tract (77.9\%), bloodstream (27.6\%), and abdomen (35.4\%) were the main sites of infection. Gram-negative infections $(33.8 \%)$ and mixed infections (35.1\%) were the primary infection types, while fungal infections accounted for $10.4 \%$. Among 
TABle 1: Demographic and clinical characteristics of the study subjects in the sepsis and control groups.

\begin{tabular}{|c|c|c|c|}
\hline Characteristics & $\begin{array}{c}\text { Cases }(n=308) \\
n(\%) \\
\end{array}$ & $\begin{array}{c}\text { Controls }(n=345) \\
n(\%)\end{array}$ & $P$ value \\
\hline Age (years) & $62.36 \pm 17.17$ & $54.90 \pm 15.73$ & 0.412 \\
\hline Male/female, $n$ & $217 / 91$ & $222 / 123$ & 0.097 \\
\hline \multicolumn{4}{|c|}{ Organ dysfunction } \\
\hline One, $n(\%)$ & $48(15.6)$ & N.A. & \\
\hline Two, $n(\%)$ & $89(28.9)$ & N.A. & \\
\hline Three or more, $n(\%)$ & $141(45.8)$ & N.A. & \\
\hline \multicolumn{4}{|c|}{ Sepsis status } \\
\hline Sepsis, $n(\%)$ & $30(9.7)$ & N.A. & \\
\hline Septic shock, $n(\%)$ & $97(31.5)$ & N.A. & \\
\hline Severe sepsis, $n(\%)$ & $181(58.8)$ & N.A. & \\
\hline \multicolumn{4}{|c|}{ Source of infection, $n(\%)$} \\
\hline Respiratory tract infection & $240(77.9)$ & N.A. & \\
\hline Primary bloodstream infection & $85(27.6)$ & N.A. & \\
\hline Wound infection & $38(12.3)$ & N.A. & \\
\hline Abdominal infection & $109(35.4)$ & N.A. & \\
\hline Urinary tract infection & $13(4.2)$ & N.A. & \\
\hline Catheter-associated infection & $25(8.1)$ & N.A. & \\
\hline Other & $19(6.2)$ & N.A. & \\
\hline \multicolumn{4}{|c|}{ Pathogens, $n(\%)$ (positive blood cultures) } \\
\hline Gram-negative & $104(33.8)$ & N.A. & \\
\hline Gram-positive & $51(16.5)$ & N.A. & \\
\hline Mixed Gram-negative and positive & $108(35.1)$ & N.A. & \\
\hline Fungus & $32(10.4)$ & N.A. & \\
\hline Negative blood cultures & $13(4.2)$ & N.A. & \\
\hline APACHE-II score & $23.1 \pm 4.7$ & N.A. & \\
\hline 28-day mortality, $n(\%)$ & 36.5 & N.A. & \\
\hline
\end{tabular}

N.A.: not Applicable; APACHE II: Acute Physiology and Chronic Health Evaluation II.

TABLE 2: Distributions of genotypes and allele frequencies in controls and patients with sepsis.

\begin{tabular}{|c|c|c|c|c|c|}
\hline Genotype & $\begin{array}{c}\text { All sepsis cases, } \\
n(\%)\end{array}$ & $\begin{array}{c}\text { Controls, } \\
n(\%)\end{array}$ & $P$ value & $P$ value ${ }^{*}$ & OR $(95 \% \mathrm{CI})$ \\
\hline Total & 308 & 345 & 0.622 & 0.629 & $\begin{array}{c}1.160 \\
(0.642-2.098)\end{array}$ \\
\hline Prol2Pro & 287 (93.18) & $318(92.17)$ & & & \\
\hline Pro12Ala & $21(6.82)$ & $27(7.83)$ & & & \\
\hline Ala12Ala & $0(0)$ & $0(0)$ & & & \\
\hline \multicolumn{6}{|l|}{ Allele } \\
\hline Pro & 595 (96.59) & $663(96.09)$ & 0.629 & 0.629 & $\begin{array}{c}1.154 \\
(0.645-2.063)\end{array}$ \\
\hline Ala & $21(3.41)$ & $27(3.91)$ & & & \\
\hline
\end{tabular}

OR: odds ratio; 95\% CI: 95\% confidence interval. ${ }^{*}$ False discovery rate adjusted $P$ value for multiple hypothesis testing using the Benjamini-Hochberg method.

the total group of sepsis patients, $45.8 \%$ exhibited three or more organ dysfunctions. Severe sepsis accounted for $58.8 \%$ of the sepsis patients. The overall 28-day mortality rate of the sepsis patients was $36.5 \%$.

3.2. Distributions of Genotypes and Allele Frequencies in Sepsis Patients and Controls. A total of 308 sepsis patients and 345 healthy control subjects were successfully analyzed for the Pro12Ala polymorphism. The genotype and allele frequency distributions of this single-nucleotide polymorphism (SNP) in the patient groups and control groups in our cohort are presented in Table 2 . The allele and genotype distributions for the assayed locus, rs1801282, of the patients with sepsis and controls indicated that both groups were in Hardy-Weinberg equilibrium $(P=0.536$ and 0.449 , resp.). The frequencies 


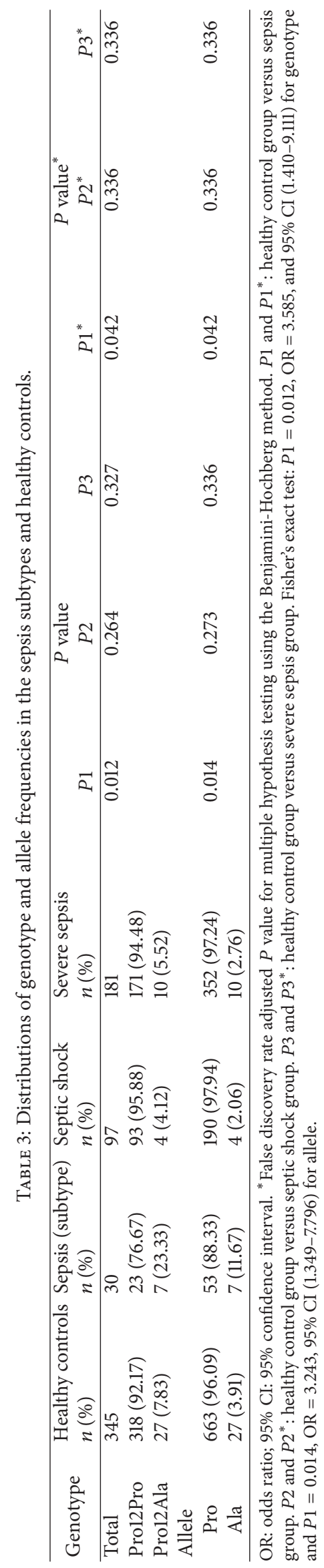


TABLE 4: Distributions of genotype and allele frequencies among surviving and nonsurviving patients.

\begin{tabular}{|c|c|c|c|c|c|}
\hline Genotype & $\begin{array}{c}\text { Survivors } \\
n(\%) \\
\end{array}$ & $\begin{array}{c}\text { Nonsurvivors } \\
n(\%)\end{array}$ & $P$ value & $P$ value ${ }^{*}$ & OR $(95 \% \mathrm{CI})$ \\
\hline Total & 196 & 112 & \multirow{3}{*}{0.002} & \multirow{3}{*}{0.002} & \multirow{3}{*}{$\begin{array}{c}12.614 \\
(1.669-95.31)\end{array}$} \\
\hline Pro12Pro & $176(89.80)$ & $111(99.11)$ & & & \\
\hline Pro12Ala & $20(10.20)$ & $1(0.09)$ & & & \\
\hline \multicolumn{6}{|l|}{ Allele } \\
\hline Pro & $372(94.90)$ & $223(99.55)$ & \multirow[t]{2}{*}{0.002} & \multirow[t]{2}{*}{0.002} & \multirow[t]{2}{*}{$\begin{array}{c}11.989 \\
(1.598-89.95)\end{array}$} \\
\hline Ala & $20(5.10)$ & $1(0.45)$ & & & \\
\hline
\end{tabular}

OR: odds ratio; 95\% CI: 95\% confidence interval. ${ }^{*}$ False discovery rate adjusted $P$ value for multiple hypothesis testing using the Benjamini-Hochberg method.

of the Pro12Pro and Pro12Ala genotypes were $93.18 \%$ and $6.82 \%$, respectively, in the case group, and $92.17 \%$ and $7.83 \%$, respectively, in the control group. None of the individuals in our study cohort had the Ala12Ala genotype.

3.3. Disease Severity and Genotype. We divided the sepsis cases into three subtypes (sepsis, septic shock, and severe sepsis) and investigated the association between the SNP and each subtype. As shown in Table 3, there were significant differences in the genotype distribution and allele frequency between the sepsis subtype and the healthy controls. The frequency of the Ala allele in the sepsis subtype was significantly higher than in the healthy controls $(P=0.014$, odds ratio $(\mathrm{OR})=3.243$, and 95\% confidence interval $(\mathrm{CI})(1.349-7.796)$ for allele and $P=0.012, \mathrm{OR}=3.585$, and 95\% CI (1.410-9.111) for genotype). Furthermore, after Benjamini-Hochberg $(\mathrm{BH})$ multiple testing correction was performed, the difference remained significant $\left(P^{*}\right.$ (corr) $=0.042$ for genotype and $P^{*}$ (corr) $=0.042$ for allele). There were no significant differences in genotype distribution or allele frequency between the healthy controls and the septic shock or severe sepsis subtype.

We also separated the sepsis cases into two groups, survivors and nonsurvivors, on the basis of the patients' 28day mortality. Only one patient in the nonsurvivor group had the Pro12Ala genotype. Significant differences in genotype and allele frequencies were found between the survivors and nonsurvivors in the overall group of sepsis patients $(P=$ $0.002, P^{*}$ (corr) $=0.002$ for genotype and $P=0.002, P^{*}$ (corr) $=0.002$ for allele) (Table 4$)$.

3.4. Mortality and Genotype. A total of $112(36.5 \%)$ patients died during hospitalization. The mortality increased with increasing severity of the disease, from $13.3 \%$ for sepsis to $32.0 \%$ and $51.5 \%$ for severe sepsis and septic shock, respectively $(P<0.001)$. The overall group of patients with sepsis (308 cases) was further divided into two groups according to genotype.

Based on a log-rank test for trend, the Ala12 allele carriers had significantly increased 28-day survival compared with the Pro12 carriers $(P=0.004)$ (Figure $1(\mathrm{a}))$. However, stratification by subtypes (sepsis subtype, severe sepsis, and septic shock) did not reveal a statistical difference between the Pro12 and the Ala12 allele carriers in sepsis patients (Figures 1(b), 1(c), and 1(d)). A small trend, although not significant, was observed between the Prol2 and the Ala12 allele carriers in septic shock patients $(P=0.078)$ (Figure $1(\mathrm{~d})$ ).

3.5. Association Analysis of the PPAR- $\gamma$ Gene Polymorphism and Sepsis Outcome in Survivors. The patients in the survivor group were divided into two groups according to their genotype. There were significant differences between the two groups in the APACHE-II score, SOFA score, duration of ICU stay, and duration of hospital stay. The patients with the Pro12Pro genotype had worse disease severity and increased recovery time compared with the patients with the Pro12Ala genotype (Table 5).

\section{Discussion}

We investigated a common SNP, Prol2Ala, in the PPAR- $\gamma$ gene in 308 patients with clinically defined sepsis and 345 age-matched healthy controls, and we evaluated the effects of this SNP on disease risk and progression. No significant differences were found in the genotype distribution and allele frequency of the PPAR- $\gamma$ Pro12Ala polymorphism between the sepsis patients and healthy controls. However, in the group of survivors, we found that carrying the Ala allele of the Pro12Ala polymorphism was significantly associated with disease severity. Based on our Kaplan-Meier survival analysis, 28-day survival was significantly reduced in individuals with the Pro12Pro genotype compared with the Prol2Ala genotype. The Ala12 carriers had lower disease severity scores, lower mortality, and faster recovery compared with the patients with wild-type genotypes. Our population-based study demonstrated that the Pro12Ala polymorphism allele might not serve as a marker for susceptibility to sepsis but could influence a patient's clinical outcome and risk of dying from sepsis.

PPAR $-\gamma$ is a nuclear receptor expressed in monocytes, macrophages, $\mathrm{T}$ cells, endothelial cells, and other cells involved in the progression of sepsis [4, 16-19]. Importantly, compared with control subjects, increases in PPAR- $\gamma$ expression and activity have been reported in T lymphocytes and polymorphonuclear neutrophils isolated from either mice or human patients with sepsis $[16,20,21]$. PPAR- $\gamma$ 


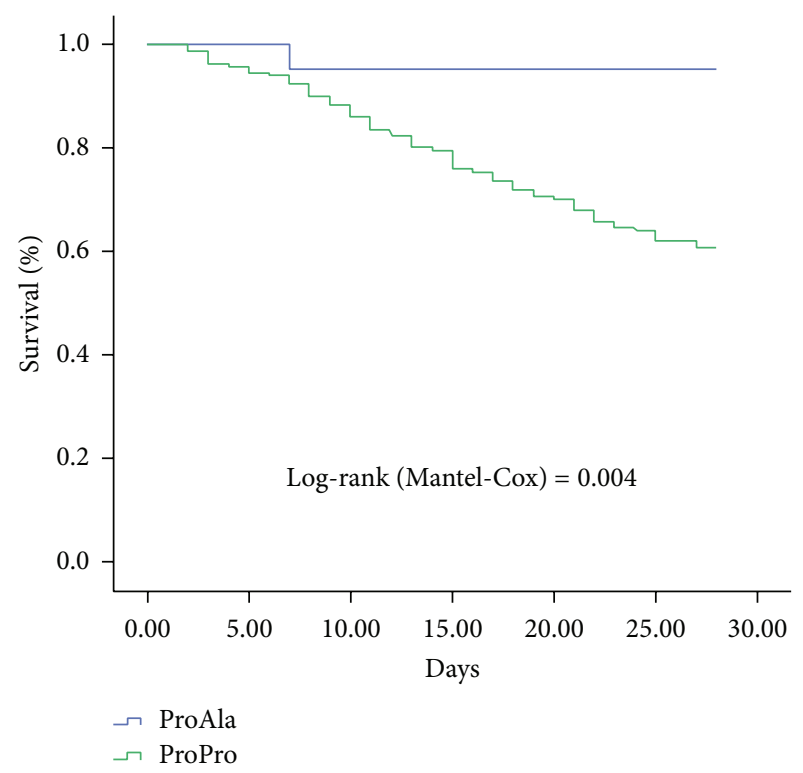

(a)

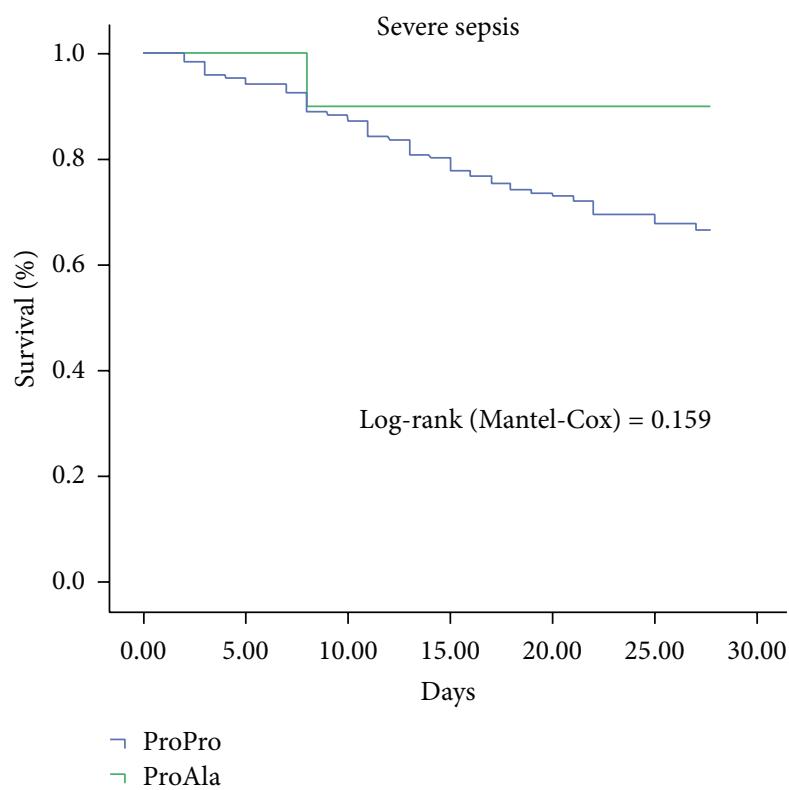

(c)

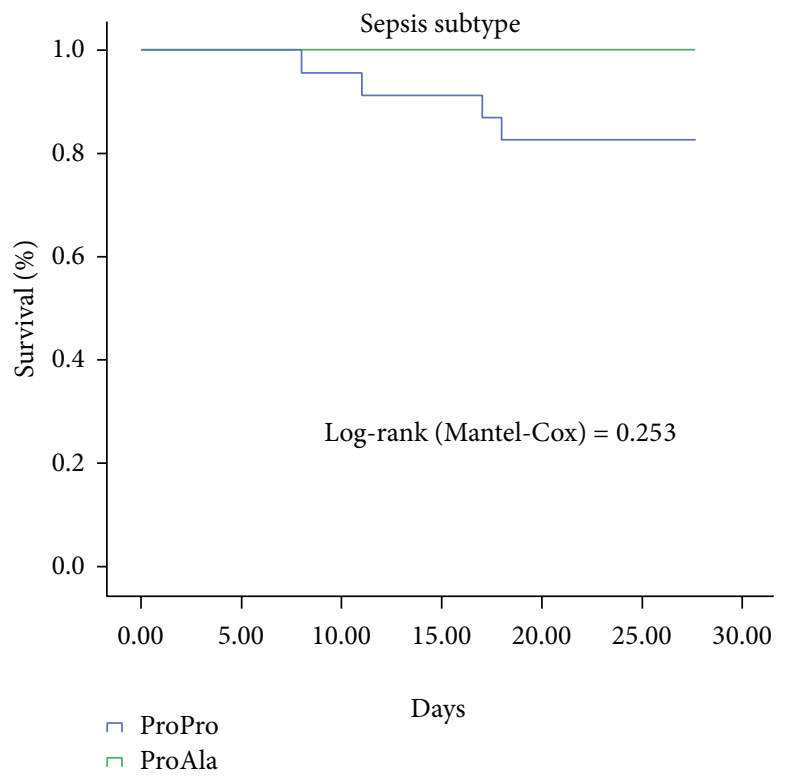

(b)

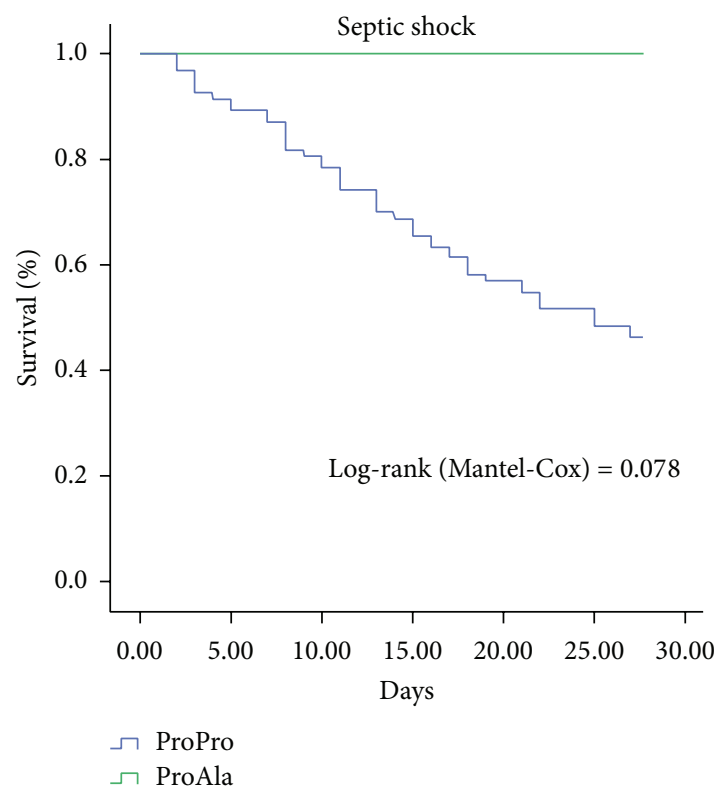

(d)

FIGURE 1: 28-day survival rates of patients with sepsis. Kaplan-Meier estimates were used to calculate the probability of 28-day survival according to the PPAR- $\gamma$ Prol2Ala genotype. The carriers of the Prol2Pro genotype had significantly decreased 28-day survival compared with the carriers of the Pro12Ala genotype. (a) Pro12Pro carriers versus Pro12Ala carriers; (b) Pro12Pro carriers versus Prol2Ala carriers in Sepsis subtype subgroup; (c) Pro12Pro carriers versus Pro12Ala carriers in severe sepsis subgroup; (d) Prol2Pro carriers versus Prol2Ala carriers in severe sepsis subgroup in septic shock subgroup.

TABlE 5: Association between genotype and sepsis outcome in the survivor group.

\begin{tabular}{lccccc}
\hline Genotype & $n$ & APACHE-II score & SOFA score & ICU stay (days) & Hospital stay (days) \\
\hline Pro12Pro & 176 & $20.78 \pm 3.7$ & $11.21 \pm 4.2$ & $18.75 \pm 3.9$ & $25.981 \pm 7.1$ \\
Prol2Ala & 20 & $15.01 \pm 3.3$ & $7.05 \pm 2.8$ & $12.33 \pm 2.4$ & $17.72 \pm 5.1$ \\
$P$ value & & 0.031 & 0.029 & 0.025 & 0.021 \\
$P$ value* $^{*}$ & & 0.031 & 0.031 & 0.031 & 0.031 \\
\hline
\end{tabular}

${ }^{*}$ False discovery rate adjusted $P$ value for multiple hypothesis testing using the Benjamini-Hochberg method. 
activation during the onset of sepsis inhibits inflammatory gene expression and can negatively interfere with proinflammatory transcription factor signaling pathways in inflammatory cells, resulting in the prevention of sepsis progression via an attenuation of the hyperinflammatory response. The body diminishes the harmful effects of the late phase of sepsis by producing anti-inflammatory cytokines and enhancing immune paralysis via immune cell apoptosis $[22,23]$. Hotchkiss and colleagues showed that the depletion of lymphocytes is the central pathogenic event during sepsis and is a major contributor to poor outcomes following sepsis [22, 24-27]. Compared with the major (Pro) allele, the minor (Ala) allele of PPAR- $\gamma$ is less biochemically active; therefore, we speculated that the improved survival and outcome of Ala carriers might be due to an attenuation of $\mathrm{T}$ cell apoptosis. Our results provide strong support for this hypothesis. In addition, the survival advantage conferred by the Ala12 allele during sepsis is also supported by in vivo studies of $\mathrm{T}$ cellspecific PPAR- $\gamma$ knockout mice and in vitro studies of PPAR$\gamma$ inhibition in T cells using the PPAR- $\gamma$ antagonist GW9662 [16].

To our knowledge, our study is the first to analyze the association between the PPAR- $\gamma$ Prol2Ala polymorphism and sepsis in a Chinese Han population. In this study, the Ala allele of the PPAR- $\gamma$ Prol2Ala polymorphism was associated with significant benefits in the clinical outcome of sepsis. Previous studies have reported that the Ala allele was correlated with lower PPAR- $\gamma$ transcriptional activity and have characterized the PPAR- $\gamma$ Prol2Ala polymorphism in a variety of inflammatory diseases, such as type 2 diabetes mellitus, atherosclerosis, ulcerative colitis, Crohn's disease, psoriatic arthritis, and diabetic nephropathy [10-12, 28, 29]. Most of these studies observed a protective effect in carriers of the Ala allele. Although the present study found no significant differences between the healthy controls and sepsis patients in the distribution of Pro12Ala genotypes or alleles, the sepsis patients in the survivor with the PPAR- $\gamma$ Prol2Ala genotype had milder disease and faster recovery than those with the Prol2Pro genotype.

The Ala12 allele frequency of the Pro12Ala SNP varies widely among continental and ethnic groups; reported Ala12 allele frequencies include 0.15 in a Finnish population, 0.12 in a German population, 0.082 in an Italian population, and 0.034 in a Chinese population [30]. In the context of sepsis, this variation might result in diverse genetic roles of this polymorphism in different populations. Therefore, it will be necessary to confirm our findings in patients of different ethnicities.

In summary, our results reveal that the PPAR- $\gamma$ Prol2Ala polymorphism is not associated with sepsis in the studied Chinese Han population, but the observed genetic difference may be important in influencing clinical outcome.

\section{Conflict of Interests}

The authors declare that there is no conflict of interests regarding the publication of this paper.

\section{Authors' Contribution}

Guoda Ma, Haiyang Wang, and Guixi Mo contributed equally to this work.

\section{Acknowledgments}

Support for this work includes funding from the National Nature Science Foundation of China (Grant nos. 31171219, 81261120404, 81271213, 81270196, and 81271214), Science and Technology Planning Project of Guangdong Province (no. 2011B03180023), the Science and Technology Innovation Fund of Guangdong Medical College (no. STIF 201101), and Doctor Startup Fund of Guangdong Medical College (no. XB1326).

\section{References}

[1] M. T. Andrades, A. Morina, S. Spasić, and I. Spasojević, "Benchto-bedside review: sepsis - from the redox point of view," Critical Care, vol. 15, no. 5, article 230, 2011.

[2] M. V. Schmidt, B. Brüne, and A. von Knethen, "The nuclear hormone receptor PPAR $\gamma$ as a therapeutic target in major diseases," TheScientificWorldJournal, vol. 10, pp. 2181-2197, 2010.

[3] A. von Knethen, M. Soller, and B. Brüne, "Peroxisome proliferator-activated receptor $\gamma(\operatorname{PPAR} \gamma)$ and sepsis," Archivum Immunologiae et Therapiae Experimentalis, vol. 55, no. 1, pp. 1925, 2007.

[4] A. von Knethen, M. Soller, N. Tzieply et al., "PPAR $\gamma 1$ attenuates cytosol to membrane translocation of $\mathrm{PKC} \alpha$ to desensitize monocytes/macrophages," Journal of Cell Biology, vol. 176, no. 5, pp. 681-694, 2007.

[5] B. Zingarelli and J. A. Cook, "Peroxisome proliferator-activated receptor- $\gamma$ is a new therapeutic target in sepsis and inflammation," Shock, vol. 23, no. 5, pp. 393-399, 2005.

[6] B. Zingarelli, M. Sheehan, P. W. Hake, M. O'Connor, A. Denenberg, and J. A. Cook, "peroxisome proliferator activator receptor- $\gamma$ ligands, 15 -deoxy- $\Delta 12,14$-prostaglandin $\mathrm{J} 2$ and ciglitazone, reduce systemic inflammation in polymicrobial sepsis by modulation of signal transduction pathways," Journal of Immunology, vol. 171, no. 12, pp. 6827-6837, 2003.

[7] Y. Tsujimura, T. Matsutani, A. Matsuda et al., "Effects of pioglitazone on survival and omental adipocyte function in mice with sepsis induced by cecal ligation and puncture," Journal of Surgical Research, vol. 171, no. 2, pp. e215-e221, 2011.

[8] Y. Zhu, C. Qi, J. R. Korenberg et al., "Structural organization of mouse peroxisome proliferator-activated receptor $\gamma(\operatorname{mPPAR} \gamma)$ gene: alternative promoter use and different splicing yield two mPPAR $\gamma$ isoforms," Proceedings of the National Academy of Sciences of the United States of America, vol. 92, no. 17, pp. 7921$7925,1995$.

[9] C. Knouff and J. Auwerx, "Peroxisome proliferator-activated receptor- $\gamma$ calls for activation in moderation: lessons from genetics and pharmacology," Endocrine Reviews, vol. 25, no. 6, pp. 899-918, 2004.

[10] W. H. Kao, J. Coresh, A. R. Shuldiner, E. Boerwinkle, M. S. Bray, and F. L. Brancati, "Prol2Ala of the peroxisome proliferatoractivated receptor- $\gamma 2$ gene is associated with lower serum insulin levels in nonobese African Americans: the atherosclerosis risk in communities study," Diabetes, vol. 52, no. 6, pp. 15681572, 2003. 
[11] C. Butt, D. Gladman, and P. Rahman, "PPAR- $\gamma$ gene polymorphisms and psoriatic arthritis," The Journal of Rheumatology, vol. 33, no. 8, pp. 1631-1633, 2006.

[12] Z. Zhang, N. Yang, G. Zhao, L. Zhu, and L. Wang, "Association between the Prol2Ala polymorphism of peroxisome proliferator-activated receptor $\gamma 2$ and inflammatory bowel disease: a meta-analysis," PLoS ONE, vol. 7, no. 1, Article ID e30551, 2012.

[13] L. Klotz, S. Schmidt, R. Heun, T. Klockgether, and H. Kölsch, "Association of the PPAR $\gamma$ gene polymorphism Prol2Ala with delayed onset of multiple sclerosis," Neuroscience Letters, vol. 449, no. 1, pp. 81-83, 2009.

[14] R. C. Bone, R. A. Balk, F. B. Cerra et al., "Definitions for sepsis and organ failure and guidelines for the use of innovative therapies in sepsis. The ACCP/SCCM Consensus Conference Committee American College of Chest Physicians/Society of Critical Care Medicine," Chest, vol. 101, no. 6, pp. 1644-1655, 1992.

[15] M. M. Levy, M. P. Fink, J. C. Marshall et al., "2001 SCCM/ ESICM/ACCP/ATS/SIS international sepsis definitions conference," Critical Care Medicine, vol. 31, no. 4, pp. 1250-1256, 2003.

[16] M. V. Schmidt, P. Paulus, A. M. Kuhn et al., "Peroxisome proliferator-activated receptor $\gamma$-induced T cell apoptosis reduces survival during polymicrobial sepsis," American Journal of Respiratory and Critical Care Medicine, vol. 184, no. 1, pp. 6474, 2011.

[17] A. T. Reddy, S. P. Lakshmi, J. M. Kleinhenz, R. L. Sutliff, C. M. Hart, and R. C. Reddy, "Endothelial cell peroxisome proliferator-activated receptor $\gamma$ reduces endotoxemic pulmonary inflammation and injury," The Journal of Immunology, vol. 189, no. 11, pp. 5411-5420, 2012.

[18] M. Matsuyama, R. Yoshimura, Y. Kawahito et al., "Relationship between peroxisome proliferator-activated receptor- $\gamma$ and renal ischemia-reperfusion injury," Molecular Medicine Reports, vol.1, no. 4, pp. 499-503, 2008.

[19] R. Yoshimura, M. Matsuyama, Y. Segawa et al., "Study of peroxisome proliferator-activated receptor (PPAR) $-\gamma$ in renal ischemia-reperfusion injury," Transplantation Proceedings, vol. 36, no. 7, pp. 1946-1948, 2004.

[20] R. C. Reddy and T. J. Standiford, "Effects of sepsis on neutrophil chemotaxis," Current Opinion in Hematology, vol. 17, no. 1, pp. 18-24, 2010.

[21] R. C. Reddy, V. R. Narala, V. G. Keshamouni, J. E. Milam, M. W. Newstead, and T. J. Standiford, "Sepsis-induced inhibition of neutrophil chemotaxis is mediated by activation of peroxisome proliferator-activated receptor- $\gamma$," Blood, vol. 112, no. 10, pp. 4250-4258, 2008.

[22] A. Ayala, D. E. Wesche-Soldato, M. Perl, J. L. Lomas-Neira, R. Swan, and C. Chung, "Blockade of apoptosis as a rational therapeutic strategy for the treatment of sepsis," Novartis Foundation Symposium, vol. 280, pp. 37-49, 2007.

[23] N. C. Riedemann, R. F. Guo, and P. A. Ward, "Novel strategies for the treatment of sepsis," Nature Medicine, vol. 9, no. 5, pp. 517-524, 2003.

[24] R. S. Hotchkiss, K. C. Chang, P. E. Swanson et al., "Caspase inhibitors improve survival in sepsis: a critical role of the lymphocyte," Nature Immunology, vol. 1, no. 6, pp. 496-501, 2000.

[25] R. S. Hotchkiss, C. M. Coopersmith, and I. E. Karl, "Prevention of lymphocyte apoptosis-a potential treatment of sepsis?" Clinical Infectious Diseases, vol. 41, supplement 7, pp. S465S469, 2005.
[26] R. S. Hotchkiss, C. M. Coopersmith, J. E. McDunn, and T. A. Ferguson, "The sepsis seesaw: tilting toward immunosuppression," Nature Medicine, vol. 15, no. 5, pp. 496-497, 2009.

[27] R. S. Hotchkiss, K. W. Tinsley, P. E. Swanson et al., "Prevention of lymphocyte cell death in sepsis improves survival in mice," Proceedings of the National Academy of Sciences of the United States of America, vol. 96, no. 25, pp. 14541-14546, 1999.

[28] X. Wang, J. Liu, Y. Ouyang, M. Fang, H. Gao, and L. Liu, "The association between the Pro12Ala variant in the PPAR $\gamma 2$ gene and type 2 diabetes mellitus and obesity in a Chinese population," PLoS ONE, vol. 8, no. 8, Article ID e71985, 2013.

[29] L. Wang, Z. Teng, S. Cai, D. Wang, X. Zhao, and K. Yu, "The association between the PPAR $\gamma 2$ Prol2Ala polymorphism and nephropathy susceptibility in type 2 diabetes: a meta-analysis based on 9,176 subjects," Diagnostic Pathology, vol. 8, no. 1, article 118, 2013.

[30] L. Yao, K. Li, L. Zhang, S. Yao, Z. Piao, and L. Song, "Influence of the Prol2Ala polymorphism of PPAR- $\gamma$ on age at onset and sRAGE levels in Alzheimer's disease," Brain Research, vol. 1291, pp. 133-139, 2009. 


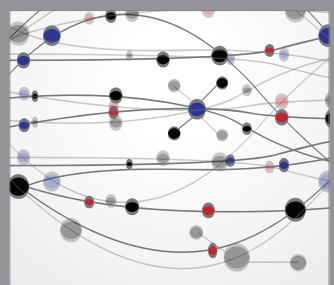

The Scientific World Journal
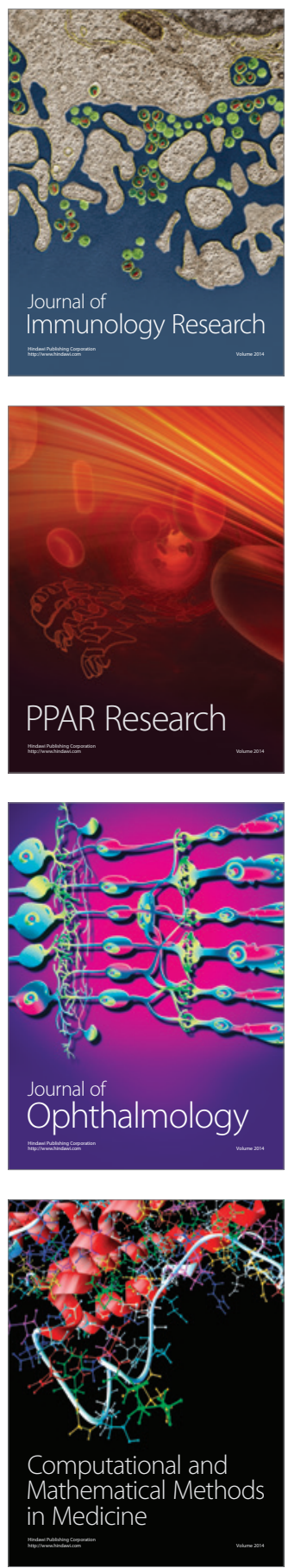

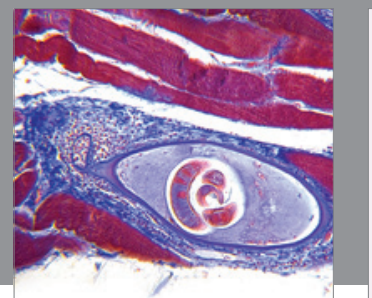

Gastroenterology

Research and Practice
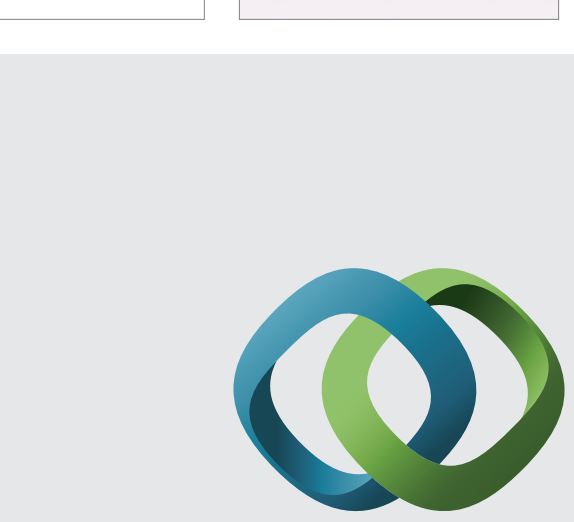

\section{Hindawi}

Submit your manuscripts at

http://www.hindawi.com
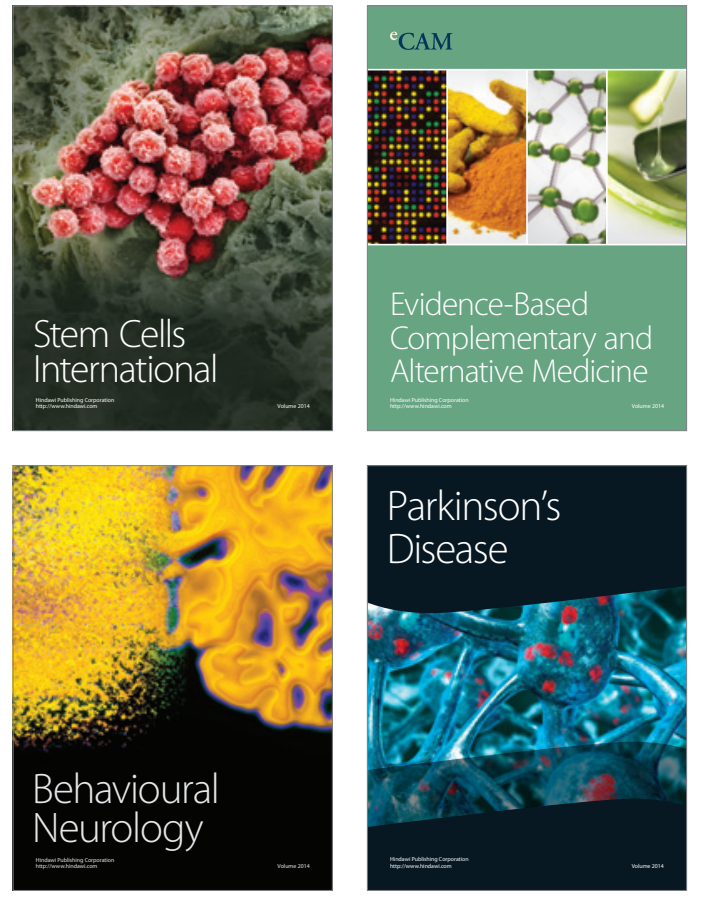
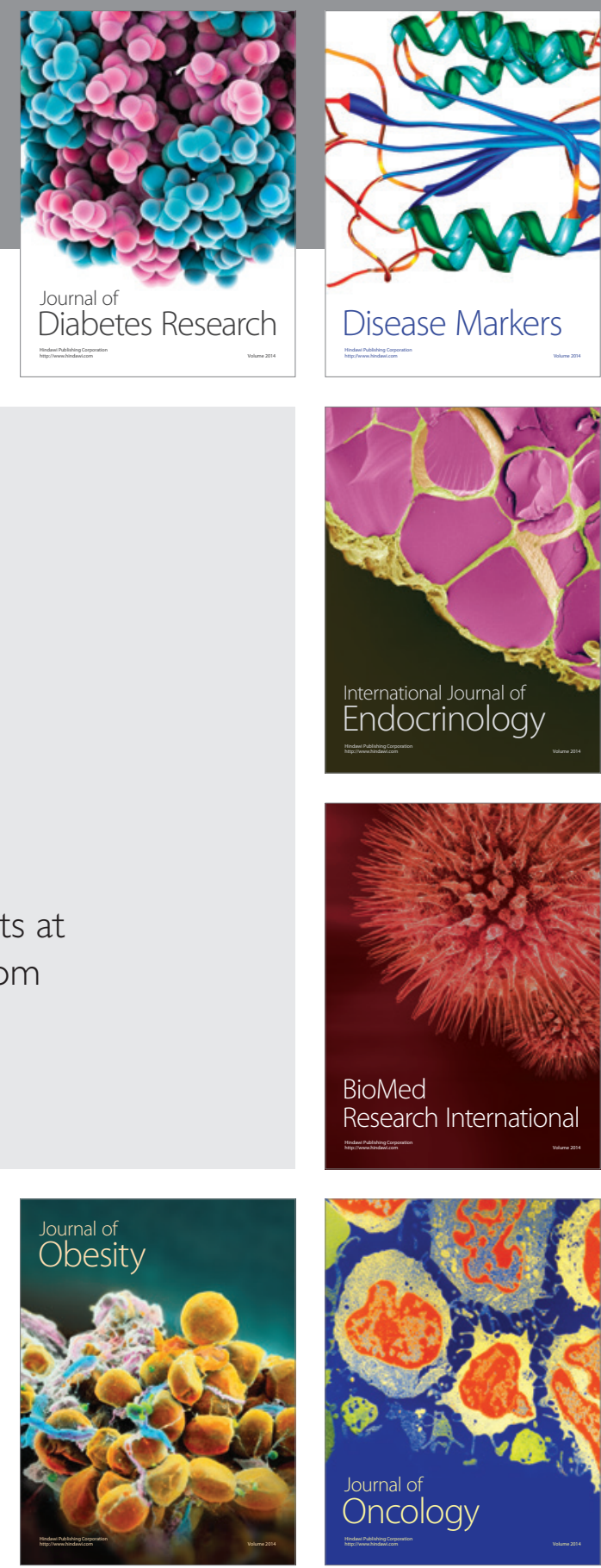

Disease Markers
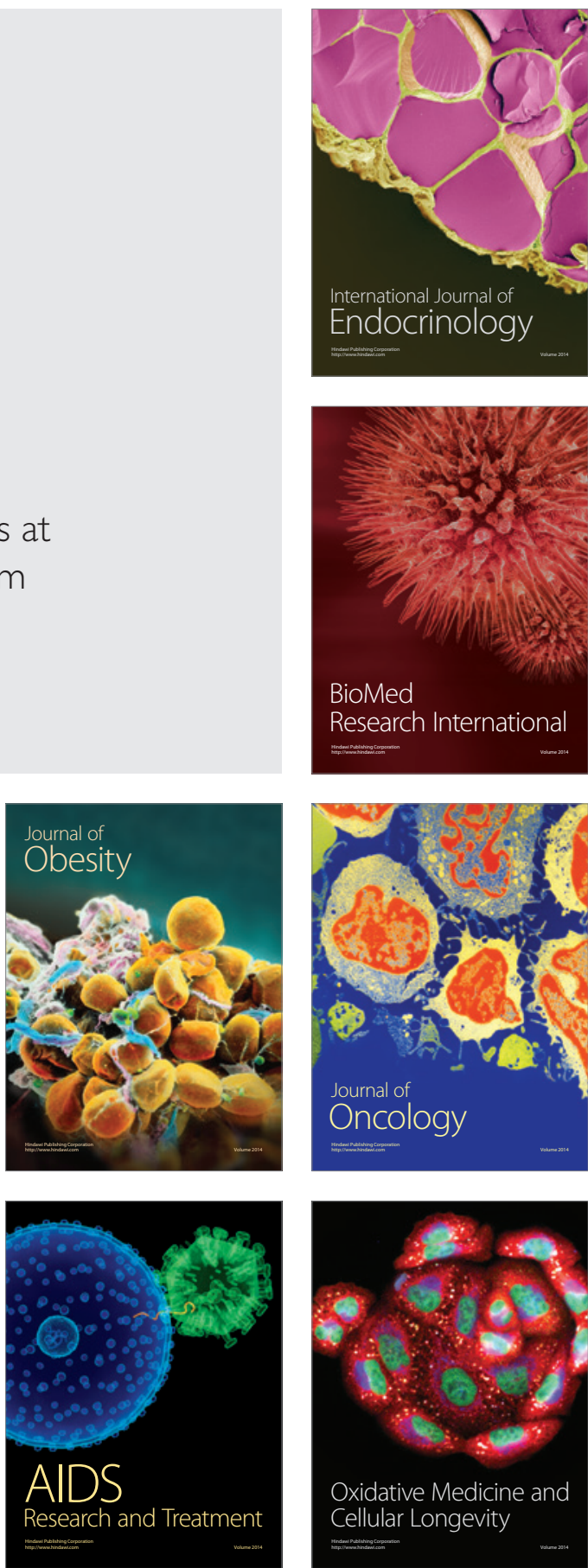